\title{
Pseudomycins, a family of novel peptides from Pseudomonas syringae possessing broad-spectrum antifungal activity
}

\author{
Leslie Harrison, ${ }^{1} \uparrow$ David B. Teplow ${ }^{2}$, Michael Rinaldi ${ }^{3}$ and Gary Strobel ${ }^{1 *}$ \\ ' Department of Plant Pathology, Montana State University, Bozeman, MT 59717, USA \\ 'Beckman Institute and Division of Biology, California Institute of Technology, Pasadena, CA 91125, USA \\ ${ }^{3}$ Audie L. Murphy Veterans Memorial Hospital, 7703 Floyd Curl Dr., San Antonio, TX 78284, USA
}

\begin{abstract}
A family of peptide antimycotics, termed pseudomycins, has been isolated from liquid cultures of Pseudomonas syringae, a plant-associated bacterium. These compounds were purified using Amberlite XAD-2 and reverse-phase liquid chromatography. Pseudomycin A, the predominant peptide in a family of four, showed selective phytotoxicity, and had impressive activity against the human pathogen Candida albicans. Amino acid, mass spectroscopic, and comparative electrophoretic and chromatographic analyses revealed that the pseudomycins are different from previously described antimycotics from $\boldsymbol{P}$. syringae, including syringomycin, syringotoxin and syringostatins. Pseudomycins A-C contain hydroxyaspartic acid, aspartic acid, serine, arginine, lysine and diaminobutyric acid. The molecular masses of pseudomycins $\mathrm{A}-\mathrm{C}$, as determined by plasma desorption mass spectrometry, are 1224, 1208 and 1252 Da, respectively. Pseudomycin D, on the other hand, has a molecular mass of $2401 \mathrm{Da}$ and is more complex than pseudomycins $\mathrm{A}-\mathrm{C}$.
\end{abstract}

\section{Introduction}

Pseudomonas syringae represents a wide range of plantassociated bacteria, some of which are pathogens, while others are weak pathogens or saprophytes (Starr et al., 1981). Many biotypes of $P$. syringae produce one or more bioactive substances that may allow the bacterium to survive in its niche; for instance, on a leaf surface where it must compete with fungi and other bacteria. A number of novel strategies for the biological control of fungal plant diseases have been developed based on this observation (Davison, 1988; Fravel, 1988; Lam et al., 1987; Sakthivel \& Gnanamanicham, 1987; Thomashow \& Weller, 1988; Voisard et al., 1989; Weller, 1988; Myers $\&$ Strobel, 1983). For example, a transposon-generated regulatory mutant of the wild-type strain of $P$. syringae 174 (MSU 16H) has been isolated that in culture produces increased zones of fungal inhibition when compared to the wild-type bacterium. Because this isolate has excellent activity against Ceratocystis ulmi, the causal agent of Dutch elm disease, it was tested in elms and shown to confer a greater protective effect than the

† Present address: Monsanto Life Sciences Research Center, 700 Chesterfield Parkway, St Louis, MO 63198, USA.

Abbreviations: 3(OH)Asp, 3-hydroxyaspartic acid; CE, capillary electrophoresis; Dab, diaminobutyric acid; PDMS, plasma desorption mass spectrometry; PTC-, phenylthiocarbamoyl-; TFA, trifluoroacetic acid. wild-type strain (Lam et al., 1987). More extensive tests on field-grown elms have confirmed the phenomenon of biocontrol at the prophylactic level (Scheffer, 1983, 1989).

Over the past several years, we have made many attempts to isolate and characterize the molecules responsible for the antimycotic activity of $P$. syringae MSU $16 \mathrm{H}$. Initially, the bioactivity appeared to be unstable when preparations were subjected to thin-layer and high-performance liquid chromatography. In addition, factors such as $\mathrm{pH}$, composition of the culture medium and temperature all seemed to affect antimycotic production. We report here the isolation of a family of peptide antimycotics termed pseudomycins, the initial chemical characterization of these molecules, and the wide spectrum of antibiotic activity they display, including activity against Candida albicans, a clinically important fungal pathogen of humans. Pseudomycins A, $B$, and $C$ are structurally related, but distinct from syringomycin and other antimycotics previously studied from other isolates of $P$. syringae (Segre et al., 1989a; Bidwai et al., 1986; Ballio et al., 1988; Gross et al., 1977; Isogai et al., 1989).

\section{Methods}

Bacterial strains and syringomycin. $P$. syringae MSU $16 \mathrm{H}$ is an elmacclimated transposon (Tn903) generated mutant of wild-type $P$. syringae MSU 174 and was used in this study because of its ability to 
Table 1. Plant-pathogenic fungi and their growth conditions

\begin{tabular}{lllc}
\hline \hline \multicolumn{1}{c}{ Fungus } & \multicolumn{1}{c}{ Source* } & \multicolumn{1}{c}{ Medium $\dagger$} & $\begin{array}{c}\text { Temp. } \\
\left({ }^{\circ} \mathrm{C}\right)\end{array}$ \\
\hline $\begin{array}{l}\text { Cephalosporium gramineum } \\
\text { Pyrenophora teres }\end{array}$ & D. Mathre, MSU & Potato dextrose agar & 23 \\
Pyrenophora graminea & M. Bjarko, MSU & Potato dextrose-V8 juice agar & 15 \\
Rynchosporium secalis & M. Bjarko, MSU & Potato dextrose-V8 juice agar & 15 \\
Ceratocystis ulmi & A. Martinez, MSU & Lima bean agar & 15 \\
Rhizoctonia solani & G. Strobel, MSU & Potato dextrose agar & 23 \\
Botrytis allii & ATCC 28268 & Potato dextrose agar & 23 \\
Sclerotinia sclerotiorum & UCD 1159 & Potato dextrose agar & 23 \\
& D. Sands, MSU & Czapek-Dox (plus yeast & 23 \\
Verticillium albo-atrum & D. Mathre, MSU, T-9 & extract) agar & 23 \\
Verticillum dahliae & D. Mathre, MSU, SS-4 & Potato dextrose agar & 23 \\
Thielaviopsis basicola & D. Mathre, MSU, CA & Potato dextrose agar & 23 \\
Fusarium oxysporum & ATCC E16322 & Corn meal agar & 23 \\
Fusarium culmorum & W. Grey, MSU & Corn meal agar & 23 \\
Fusarium graminearum & W. Grey, MSU & Corn meal agar & 23 \\
\hline \hline
\end{tabular}

* MSU, Montana State University.

$\dagger$ All media formulations were obtained from the Difco Manual, 1984. V8 juice (commercially available) was added at $18 \mathrm{ml} \mathrm{I}^{-1}$.

make elevated amounts of antimycotics. It is equivalent to strain MSU 206 described by Lam et al. (1987); however, it had been inoculated into elm trees and reisolated 2 years later. The presence and location of the transposon in the bacterial genome was identical in all respects to $P$. syringae MSU 206. The wild-type, obtained from Dr David Sands, Montana State University, was isolated from a barley field in Montana. $P$. syringae MSU $16 \mathrm{H}$ was stored in $15 \%(\mathrm{v} / \mathrm{v})$ glycerol at $-70^{\circ} \mathrm{C}$. Transfers were made every two weeks to Difco Pseudomonas agar F (Difco, 1984). The optimum culture conditions for antimycotic production were found to be potato dextrose in broth (PDB) in still culture at $23^{\circ} \mathrm{C}$ for $6 \mathrm{~d}$. Generous quantities of purified syringomycin $\mathrm{E}$ (referred to in this work as 'syringomycin') were supplied by Dr John Takemoto, Department of Biology, Utah State University, Logan, Utah, USA.

Fungal strains. The sources and growth conditions of the fungal strains used to test antimycotic activity are listed in Table 1.

Plant materials. Plant materials used for testing the phytotoxic activity of the antimycotics were obtained from the MSU collection, Plant Growth Center, Montana State University. All plants were grown under controlled conditions at $28^{\circ} \mathrm{C}$ with $8 \mathrm{~h}$ of darkness and $16 \mathrm{~h}$ of light per day with a relative humidity of $30 \% \pm 10 \%$.

Pseudomycin isolation procedure. Pseudomycins were initially extracted from 1 litre of culture supernatants of $P$. syringae strain MSU $16 \mathrm{H}$ by partitioning into 1 vol. 1-butanol for $60 \mathrm{~min}$ at $22^{\circ} \mathrm{C}$. Later extractions were done with acetone. After incubation, the mixture was centrifuged at $5000 \mathrm{~g}$ for $10 \mathrm{~min}$. The supernatant was rotary evaporated to $200 \mathrm{ml}$ then brought to a final concentration of $60 \%(\mathrm{v} / \mathrm{v})$ acetone. This mixture was allowed to precipitate overnight at $4{ }^{\circ} \mathrm{C}$ with gentle stirring, then centrifuged at $5000 \mathrm{~g}$ for $10 \mathrm{~min}$. The resulting supernatant was rotary evaporated to dryness, resuspended in 1 litre of $0.1 \%(\mathrm{v} / \mathrm{v})$ trifluoroacetic acid (TFA), and loaded on an Amberlite XAD-2 column $\left(1.6 \times 40 \mathrm{~cm}\right.$, mesh size 20-60) at $1 \mathrm{ml} \mathrm{min}^{-1}$ (Bidwai et al., 1986). Pseudomycin was eluted with a nonlinear gradient of $0-100 \%(v / v) 1$-propanol in $0.1 \%$ TFA and the column eluate monitored at $254 \mathrm{~nm}$ according to Bidwai et al. (1986). Fractions were collected and tested for antifungal activity. Active fractions were pooled, dried by rotary evaporation, resuspended in $1.0 \mathrm{ml} 50 \% 1$ propanol in $0.1 \%$ TFA, and filtered through a $0.2 \mu \mathrm{m}$ Millipore filter. At this point the compounds were subjected to high-pressure liquid chromatography (HPLC) by injection onto a $4.6 \times 100 \mathrm{~mm} \mathrm{C-8} \mathrm{column}$ (Amicon MC-250). Retentates were eluted with a convex gradient of $0 \% 1$-propanol in $0.1 \%$ TFA to $30 \% 1$-propanol in $0.1 \%$ TFA over 35 min (Waters no. 2) at a flow rate of $1 \mathrm{ml} \mathrm{min}^{-1}$. Peaks $(254 \mathrm{~nm}$ ) were collected, evaporated, redissolved in $50 \% 1$-propanol $/ 0.1 \% \mathrm{TFA}$, then assayed. All peaks containing bioactivity were subjected to reversephase HPLC utilizing a second solvent system. Elution was accomplished with a 20 min linear gradient of $0-80 \%$ acetonitrile in $0.1 \%$ TFA at a flow rate of $1 \mathrm{ml} \mathrm{min}^{-1}$ according to standard procedures.

Thin-layer chromatography (TLC). Chromatography was done using aqueous solvents containing $\mathrm{n}$-butanol, glacial acetic acid, and either pyridine, picoline or lutidine in a ratio of 15 (water) $: 10: 3: 12$ (by vol.) using Kieselgel $F_{254}$ precoated TLC silica gel plates. Detection was done with an alcoholic ninhydrin spray.

Capillary electrophoresis $(C E)$. This was performed on an Applied Biosystems model $270 \mathrm{~A}$ instrument. Samples of the antimycotics were loaded into a $50 \mu \mathrm{m} \times 72 \mathrm{~cm}$ fused silica capillary by vacuum aspiration, then electrophoresed at $25 \mathrm{kV}, 24 \mu \mathrm{A}, 38^{\circ} \mathrm{C}$, in $50 \mathrm{~mm}-$ sodium phosphate, adjusted to $\mathrm{pH} 2.5$ with concentrated phosphoric acid. Peaks were detected at $200 \mathrm{~nm}$. 'Phe' peaks (peak eluting with retention time of phenylalanine; see next section) were dissolved in $20 \mu \mathrm{l}$ water, loaded as above, then electrophoresed at $25 \mathrm{kV}, 66 \mu \mathrm{A}$, $38^{\circ} \mathrm{C}$, in $150 \mathrm{~mm}$-sodium borate, $\mathrm{pH} 8.6$, containing $100 \mathrm{~mm}$-sodium dodecyl sulphate. The absorbance of the effluent was monitored at $254 \mathrm{~nm}$.

Amino acid analysis. Amino acid compositions were determined using an Applied Biosystems model 420A/130A derivatizer-analyser. Briefly, approximately $200-900 \mathrm{pmol}$ of each sample, mixed with $1 \mathrm{nmol} \mathrm{L-norleucine,} \mathrm{was} \mathrm{dried} \mathrm{in} \mathrm{vacuo} \mathrm{in} \mathrm{separate} 6 \times 50 \mathrm{~mm}$ glass tubes. These tubes were then sealed, in vacuo, inside $18 \times 150 \mathrm{~mm}$ Pyrex culture tubes containing $300 \mu l 6 \mathrm{M}$-hydrochloric acid (Pierce Chemical Co.). Gas-phase hydrolysis was performed by heating at $170^{\circ} \mathrm{C}$ for $30-45 \mathrm{~min}$. After cooling, each sample tube was removed from the ignition tube and dried in a Speed-Vac concentrator (Savant). 
Hydrolysis products were dissolved in $15 \mu \mathrm{l} 0.025 \%(\mathrm{w} / \mathrm{v}) \mathrm{K}_{3} \mathrm{H}$ ethylenediaminetetra-acetate (EDTA) and spotted onto the glass reaction slides of the model $420 \mathrm{~A} / 130 \mathrm{~A}$ instrument. Phenylthiocarbamoylation and reverse-phase HPLC were performed automatically by the $420 \mathrm{~A} / 130 \mathrm{~A}$ instrument, essentially according to the manufacturer's instructions. 'Phe' peaks were collected and dried down prior to $\mathrm{CE}$. Moles of each amino acid were first determined using molar absorptivity values derived from hydrolysed amino acid standards, then were normalized using the internal standard L-norleucine. 3Hydroxyaspartic acid eluted in a region containing an injection artifact, prior to any of the other amino acids. Although the presence or absence of 3-hydroxyaspartic acid could be determined, accurate quantification was not possible because its peak could not be resolved completely from this artifact.

Protein sequence analysis. Sequencing was done on polybrene-coated glass fibre supports using an Applied Biosystems model 477A/120A pulsed liquid sequenator, essentially as suggested by the manufacturer. Phenylthiohydantoin amino acid analysis was performed on-line and sequence assignments were made by visual inspection of chromatograms.

Plasma desorption mass spectrometry (PDMS). Spectra were acquired using a Biolon 20 instrument (BIO-ION Nordic; now a division of Applied Biosystems), according to the manufacturer's instructions. Samples were dissolved in $0.1 \%$ TFA $/ 50 \%$ ethanol (in water), dried on nitrocellulose-coated aluminized mylar supports, washed briefly with water, then analysed. Alkaline hydrolyses were done by incubating $2.5 \mu \mathrm{l}$ (about $0 \cdot 1-1 \mathrm{nmol}$ ) of sample (from the acetonitrile/C-8 HPLC step) with $20 \mu \mathrm{l} 1 \%(\mathrm{v} / \mathrm{v})$ ammonium hydroxide (in water) containing either $50 \%(\mathrm{v} / \mathrm{v})$ ethanol or $50 \%(\mathrm{v} / \mathrm{v})$ n-propanol, for $20 \mathrm{~min}$ at $22^{\circ} \mathrm{C}$. The samples were then dried in a Speed-Vac concentrator, dissolved in $0.1 \%$ TFA/alcohol (the same alcohol as was used for hydrolysis), and prepared for PDMS as described above.

Bioassays. Fractions to be tested for antimycotic activity were applied in $10 \mu \mathrm{g}$ quantities onto a plate of potato dextrose agar (PDA) and allowed to dry. The plate was oversprayed with a cell suspension of Geotrichum candidum in water $\left(10^{6}\right.$ conidia $\left.\mathrm{ml}^{-1}\right)$ and incubated overnight at room temperature. The diameter of the zone of complete inhibition was noted

To test for phytotoxicity, pseudomycin A was dissolved in $0.05 \%$ TFA and applied to the leaf using a leaf puncture droplet overlay technique (Sugawara et al., 1985). The leaves were incubated for $3 \mathrm{~d}$ at $23{ }^{\circ} \mathrm{C}$ under $12 \mathrm{~h}$ of fluorescent light $\left(25 \mu \mathrm{E} \mathrm{m}^{-2} \mathrm{~s}^{-1}\right)$.

To demonstrate antifungal activity, partially purified pseudomycins (Amberlite column step) were dissolved at $10 \mu \mathrm{g}^{-1}$ in $50 \% 1$-propanol in $0.1 \%$ TFA, and $10 \mu \mathrm{l}$ was then spotted onto the appropriate solid medium (Table 1) and allowed to dry. Each plate was oversprayed with a suspension of the fungus in water (about $10^{4}-10^{6}$ spores or hyphal fragments $\mathrm{ml}^{-1}$ ), sealed with Parafilm, and incubated accordingly (Table 1). In each case, a positive control (solventextracted medium without bacterium) was tested with no inhibitory effect.

Dilution tests were used to determine the minimal inhibitory concentration (MIC) of pseudomycin A against fungal pathogens of humans. Serial dilutions of purified pseudomycin $A$ in water, ranging in concentration from $50 \mathrm{ng} \mathrm{ml}^{-1}$ to $50 \mu \mathrm{g} \mathrm{ml}^{-1}$, were dispensed into tubes. Each tube $\left(10^{4}\right.$ cells $\left.\mathrm{ml}^{-1}\right)$ was then inoculated with a standardized suspension of yeasts in Sabouraud dextrose agar or other fungi in potato flakes agar (Rinaldi \& Howell, 1988). Yeasts were incubated at $30^{\circ} \mathrm{C}$; other fungi were incubated at room temperature. Growth in the experimental tubes was assessed when the positive control, broth and fungi without pseudomycin A, showed growth.

\section{Table 2. Antimycotic activity of heat-treated pseudomycins}

A 1-butanol extract $(75 \mu \mathrm{l})$ of pseudomycins, at a concentration of $33 \mu \mathrm{g} \mathrm{I}^{-1}$, was placed into each of eight $1.5 \mathrm{ml}$ Eppendorf tubes [or Reactivials (Pierce) for the $100^{\circ} \mathrm{C}$ test]. Tubes were then incubated at each of four temperatures $\left(15,30,60\right.$ and $\left.100^{\circ} \mathrm{C}\right)$ for $4 \mathrm{~d}$. Samples $(5 \mu \mathrm{l})$ were removed from each tube at $0,0 \cdot 5,1,2,4,8$, $24,48,72$ and $96 \mathrm{~h}$ and spotted on a PDA plate. After drying, the plates were oversprayed with $G$. candidum $\left(10^{6}\right.$ cells $\left.\mathrm{ml}^{-1}\right)$, then incubated at room temperature overnight. Zones of growth inhibition were recorded as $++(>2 \mathrm{~cm}),+(\leqslant 2 \mathrm{~cm})$, or - (no inhibition). The experiment was repeated twice with identical results.

\begin{tabular}{ccccccccccc}
\hline \hline $\begin{array}{c}\text { Treatment } \\
\text { temp. } \\
\left({ }^{\circ} \mathrm{C}\right)\end{array}$ & 0 & $0 \cdot 5$ & 1 & 2 & 4 & 8 & 24 & 48 & 72 & 96 \\
\hline & \cline { 1 - 6 } \\
15 & ++ & + & ++ & ++ & + & + & ++ & + & + & + \\
30 & ++ & ++ & ++ & ++ & ++ & + & ++ & + & + & + \\
60 & + & + & + & + & + & + & + & + & + & + \\
100 & ++ & + & + & + & - & - & - & - & - & - \\
\hline \hline
\end{tabular}

\section{Results and Discussion}

\section{Stability}

The chief difficulty in isolating pseudomycin has been its lability. A series of tests were done to determine the factors affecting the biological activity of this compound. Heat stability of crude pseudomycins (1-butanol step) was tested at $15,30,60$ and $100^{\circ} \mathrm{C}$ over a $96 \mathrm{~h}$ period (Table 2). Full activity was apparent up to $24 \mathrm{~h}$ at 15 and $30{ }^{\circ} \mathrm{C}$. A decrease, but not complete loss, of activity was observed at 15,30 and $60^{\circ} \mathrm{C}$ after $24 \mathrm{~h}$, and $100^{\circ} \mathrm{C}$ treatments exceeding $4 \mathrm{~h}$ resulted in the complete loss of activity.

1-Butanol extracts of pseudomycins were also treated with different solvents in order to determine which ones might be used in the purification scheme without destroying biological activity (Table 3). Pseudomycins were stable in water, alcohols, acetonitrile in $0.1 \% \mathrm{TFA}$, and $2 \mathrm{M}$ aqueous TFA. Some lability was observed with $3 \mathrm{M}$-TFA and with $0.5-2 \mathrm{M}-\mathrm{HCl}$, but only $4 \mathrm{M}-\mathrm{HCl}$ completely destroyed the biological activity present in the pseudomycin preparation. However, the most critical factor affecting pseudomycin activity was $\mathrm{pH}$. Exposure to buffers in the $\mathrm{pH}$ range $5 \cdot 4-10 \cdot 0$ completely inactivated the pseudomycins (Table 3). Buffers at pH 3.1 and $\mathrm{pH} 4.8$ had no effect. Taken together, these data show pseudomycin to be relatively heat-resistant and hydrophobic, highly resistant to inactivation by acids, but very sensitive to alkaline inactivation. As a result, pseudomycin preparations were kept at room temperature and in acidic solvents during the course of purification. 


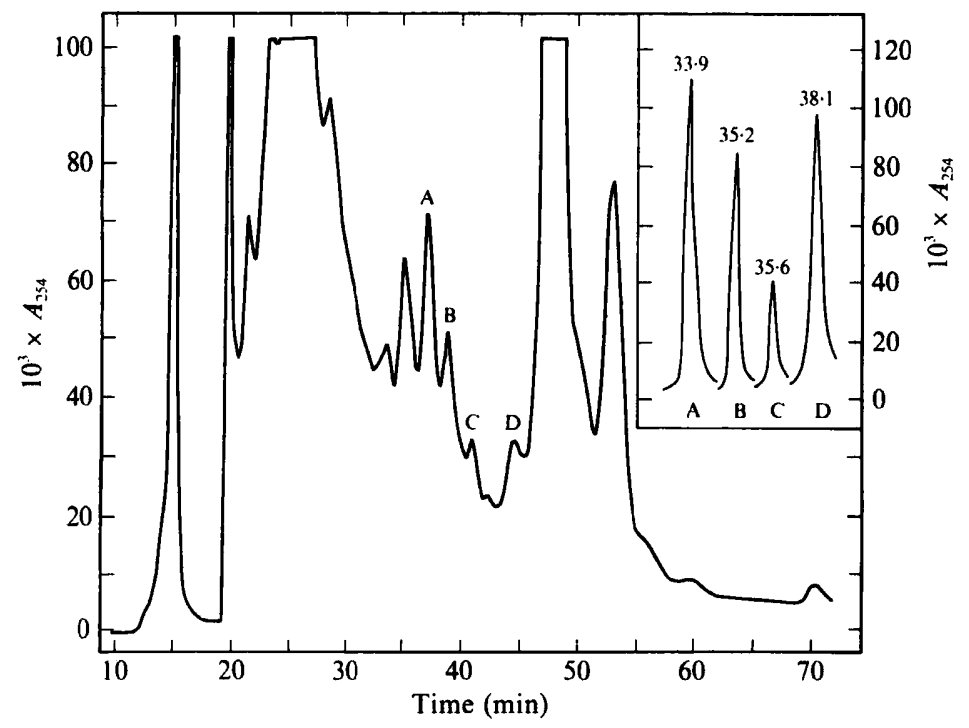

Fig. 1. HPLC purification of pseudomycins A-D. The pseudomycin fraction from Amberlite XAD-2 chromatography was resolved into its four components by reversed-phase HPLC using a C-8 column and a hyperbolic gradient of 1-propanol in TFA. Letters refer to the respective pseudomycins, A-D. Each pseudomycin fraction was then rechromatographed on the same column, but was eluted with a linear gradient of acetonitrile in TFA. A composite chromatograph of the four single peaks, and the retention times ( $\mathrm{min}$ ), observed in these second runs is presented in the inset. See Methods for experimental details.
Table 3. Effects of solvent and $p H$ on the antimycotic activity of the pseudomycins

\begin{tabular}{lccc}
\hline \multicolumn{1}{c}{ Solvent } & $\begin{array}{c}\text { Antimycotic } \\
\text { activity* }\end{array}$ & Buffer & Inhibitiont \\
\hline $100 \%$ 1-butanol & ++ & Citrate, pH 3.1 & + \\
$50 \%$ 1-propanol & ++ & Citrate, pH 4.8 & + \\
$100 \%$ 1-propanol & ++ & Acetate, pH 5.4 & - \\
$100 \%$ methanol & ++ & PIPES, pH 6.8 & - \\
$100 \%$ water & ++ & Tris, pH 8.0 & - \\
$0.1 \% \mathrm{TFA}_{10 \%} \mathrm{CH}_{3} \mathrm{CN}$ in 0.1\% TFA & ++ & Borate, pH 9.0 & - \\
$90 \% \mathrm{CH}$ CN in 0.1\% TFA & ++ & & - \\
$0.5 \mathrm{M}-\mathrm{TFA}$ & ++ & & \\
$1 \mathrm{M}-\mathrm{TFA}$ & ++ & & \\
$2 \mathrm{M}-\mathrm{TFA}$ & ++ & & \\
$3 \mathrm{M}-\mathrm{TFA}$ & + & & \\
$0.5 \mathrm{M}-\mathrm{HCl}$ & + & \\
$1 \mathrm{M}-\mathrm{HCl}$ & + & \\
$2 \mathrm{M}-\mathrm{HCl}$ & + & \\
$4 \mathrm{M}-\mathrm{HCl}$ & - & \\
\hline \hline
\end{tabular}

* A 1-butanol extract of pseudomycins $\left(5 \mu 1\right.$ at $\left.33 \mu \mathrm{g} \mu \mathrm{l}^{-1}\right)$ was added to $100 \mu \mathrm{l}$ of each solvent. Each solvent $(100 \mu \mathrm{l})$ was used as a negative control. The solutions were incubated at $23^{\circ} \mathrm{C}$ for $24 \mathrm{~h}$, then dried under $\mathrm{N}_{2}$ and resuspended in $15 \mu \mathrm{l}$ methanol. Each methanol extract $(10 \mu \mathrm{l})$ was then spotted on a PDA plate, after which the plate was dried, oversprayed with $G$. candidum $\left(10^{6}\right.$ cells $\left.\mathrm{ml}^{-1}\right)$, and incubated at room temperature overnight. Zones of growth inhibition were recorded as $++(>2 \mathrm{~cm}),+(\leqslant 2 \mathrm{~cm})$, or - (no inhibition). No inhibition of fungal growth was observed with any of the controls (data not shown).

$\dagger$ Duplicate $5 \mu \mathrm{l}$ aliquots of a 1-butanol extract of pseudomycin $\left(100 \mu \mathrm{g} \mathrm{Il}^{-1}\right)$ were dissolved in $200 \mu \mathrm{l}$ of $10 \mathrm{~mm}$-buffer. After incubation for $48 \mathrm{~h}$ at room temperature, a $10 \mu \mathrm{l}$ aliquot was bioassayed as described above. Zones of growth inhibition were recorded as + $(\leqslant 2 \mathrm{~cm})$ or - (no inhibition). Positive controls, using methanol instead of buffers, showed clear zones of inhibition. Negative controls, using buffers alone, showed no inhibition. The experiment was repeated twice with essentially the same results.

\section{Purification of pseudomycin}

Pseudomycins were purified from acetone extracts of culture supernatants through a three-step liquid chromatographic procedure using column/eluant combinations of an Amberlite XAD-2/1-propanol step, followed by C-8/1-propanol, and C-8/acetonitrile. Fractions with biological activity from the XAD-2 system were pooled and run on the first $\mathrm{C}-8$ system, producing the chromatogram shown in Fig. 1. Biologically active material was found in fractions $A-D$, which were further purified on the second C-8 system, yielding sharp, single peaks (Fig. 1, inset). The yield of the most abundant material, pseudomycin A, was $1.5 \mathrm{mg}$ per litre of culture supernatant.

\section{Purity of pseudomycins}

Capillary electrophoresis (CE) and TLC were used in addition to HPLC to assess the purity of the pseudomycin preparations. In addition, since other strains of $P$. syringae produce syringomycin, an antimycotic with chromatographic properties similar to those of the pseudomycins, we used CE and TLC to determine whether syringomycin was identical to one of the pseudomycins.

Pseudomycins A, B, C and D each produced a single, sharp, major peak in CE (data not shown); these peaks represented $95 \%, 94 \%, 95 \%$ and $98 \%$, respectively, of the total UV-absorbing material present in each fraction. Syringomycin also displayed a single, predominant peak, containing $83 \%$ of the total UV-absorbing material in the preparation (data not shown). All five samples were 


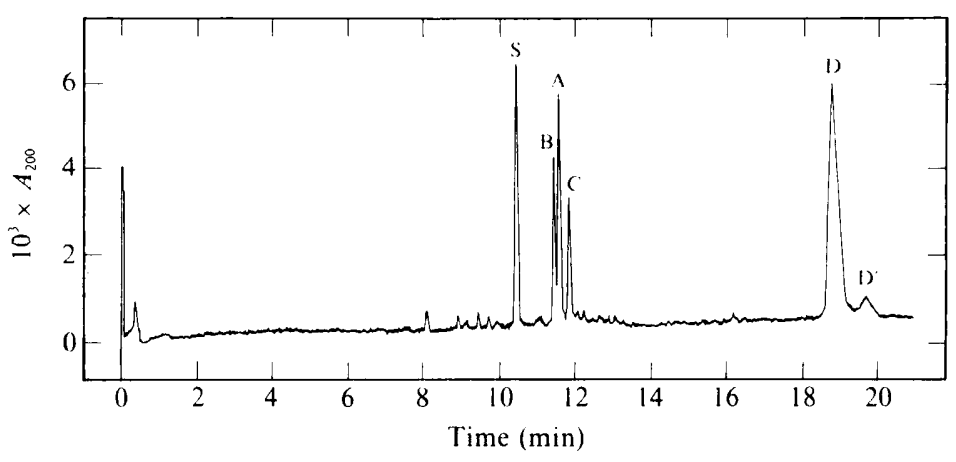

Fig. 2. CE of syringomycin and pseudomycins. Approximately $3 \mathrm{nl}$ each of syringomycin and pseudomycins A$D$ were loaded into the capillary. Electrophoresis was performed as specified in Methods. The abscissa represents electrophoretic migration time, measured from the anodic end of the capillary to the detector. Peaks are denoted as follows: S, syringomycin; A, B, C, D and D', pseudomycins A, B, C, D, and a minor component found with pseudomycin $\mathrm{D}$, respectively. then electrophoresed together to determine if any comigrated. All had unique electrophoretic mobilities (Fig. 2 ). To ensure that loading order did not affect migration times, the pairs of pseudomycins A plus B and A plus C were re-electrophoresed after loading in both possible orders. The relative electrophoretic mobilities for the three samples remained constant (data not shown). The mobility differences of syringomycin and pseudomycin $D$ relative to the triplet of $A, B$ and $C$ are so large that loading order would not affect their relative positions.

TLC experiments yielded analogous results. Each of the pseudomycins and syringomycin migrated as a single spot with a unique $R_{F}$, value in each of the different TLC systems (data not shown). In all cases, syringomycin migrated with a higher $R_{F}$ than did the pseudomycins.

The HPLC, CE and TLC results were mutually consistent and suggested that each of the four pseudomycin molecules, and syringomycin, was structurally unique. However, the modest magnitude of the physicochemical differences among these molecules, and the fact that they share certain biological activities, suggested that these five antibiotics might be related. Since the structure of syringomycin was known (Segre et al., $1989 a$ ), we used it as a comparative standard and as a control in subsequent analytical work.

\section{Mass spectral analyses}

Mass spectrometric measurements of the molecular masses of the pseudomycins were done as a first step towards defining their structures. Each molecule produced a single, predominant, protonated molecular ion (Table 4). No two masses were identical, a result consistent with the unique chromatographic and electrophoretic behaviour of each molecule. The similarity in mass among pseudomycins A-C and syringomycin establish these molecules within one family, quite distinct from the relatively massive pseudomycin $\mathrm{D}$ molecule. The mass of the protonated molecular ion of syringomycin, 1226.6, is within the 1225-1227 mass range reported by Ballio et al. (1989). These authors also

\section{Table 4. Mass spectral analysis of pseudomycins}

The pseudomycins (Pseudo. A-D) and syringomycin were analysed by PDMS, as described in Methods. Masses are those of the most predominant $(\mathbf{M}+\mathbf{H})^{+}$ions. Samples were run both without being hydrolysed and after alkaline hydrolysis in either ethanol or 1-propanol.

\begin{tabular}{lccccc}
\hline \hline \multicolumn{1}{c}{ Treatment } & $\begin{array}{c}\text { Pseudo. } \\
\text { A }\end{array}$ & $\begin{array}{c}\text { Pseudo. } \\
\text { B }\end{array}$ & $\begin{array}{c}\text { Pseudo. } \\
\text { C }\end{array}$ & $\begin{array}{c}\text { Pseudo. } \\
\text { D }\end{array}$ & $\begin{array}{c}\text { Syringo- } \\
\text { mycin }\end{array}$ \\
\hline None & $1224 \cdot 7$ & $1208 \cdot 6$ & $1252 \cdot 6$ & $2401 \cdot 0$ & $1226 \cdot 6$ \\
$\mathrm{NH}_{3}+\mathrm{C}_{2} \mathrm{H}_{5} \mathrm{OH}$ & $1270 \cdot 4$ & $1253 \cdot 3$ & $1296 \cdot 9$ & $2384 \cdot 5$ & $1272 \cdot 0$ \\
& $1243 \cdot 5$ & $1226 \cdot 1$ & $1270 \cdot 1$ & & $1243 \cdot 3$ \\
& & & & & $1208 \cdot 4$ \\
$\mathrm{NH}_{3}+\mathrm{C}_{3} \mathrm{H}_{7} \mathrm{OH}$ & $1284 \cdot 7$ & $1264 \cdot 3$ & $1311 \cdot 7$ & $2384 \cdot 9$ & $1284 \cdot 1$ \\
& $1242 \cdot 2$ & $1226 \cdot 6$ & $1269 \cdot 8$ & & $1243 \cdot 0$ \\
\hline \hline
\end{tabular}

identified dehydration products and fatty acid side-chain isomers of syringomycin which displayed mass differences of $18 \mathrm{Da}$ (atomic mass units) and $28 \mathrm{Da}$, respectively. It is possible that the mass differences between pseudomycins $\mathrm{A}$ and $\mathrm{B}$, and between $\mathrm{A}$ and $\mathrm{C}$, are due to these structural changes. Alternatively, pseudomycins $A$ and $B$ may differ by the presence or absence, respectively, of a hydroxyl group (16 Da net).

We had noted that the pseudomycins retained their biological activity after incubation in organic solvents and aqueous acids $(<4 \mathrm{M})$, but lost activity when treated with aqueous bases (Table 3 ). The acid lability could certainly be ascribed, in part, to peptide bond hydrolysis. The base lability could not be due simply to alkaline peptide bond hydrolysis because it was evident even near neutrality. These data suggested that the pseudomycins had structures exceptionally resistant to solvent-induced denaturation, but susceptible to alkaline inactivation. A cyclic lactone, such as that found in syringomycin (Segre et al., 1989b), would have these characteristics.

We tested the susceptibility of the pseudomycins and syringomycin to alkaline hydrolysis by treating the samples briefly with ammonium hydroxide (as described in Methods), then analysing them by PDMS (Table 4). 
Table 5. Amino acid composition of pseudomycins

\begin{tabular}{|c|c|c|c|c|c|}
\hline \multirow[b]{2}{*}{$\begin{array}{l}\text { Amino } \\
\text { acid }\end{array}$} & \multicolumn{5}{|c|}{ Molar percentage* } \\
\hline & $\begin{array}{c}\text { Pseudo. } \\
\text { A }\end{array}$ & $\begin{array}{l}\text { Pseudo. } \\
\text { B }\end{array}$ & $\begin{array}{l}\text { Pseudo. } \\
\text { C }\end{array}$ & $\begin{array}{c}\text { Pseudo. } \\
\text { D }\end{array}$ & $\begin{array}{c}\text { Syringo- } \\
\text { mycin }\end{array}$ \\
\hline 3(OH)Asp $\dagger$ & + & + & + & - & + \\
\hline Asx & $14 \cdot 1(1)$ & $14 \cdot 7(1)$ & $16 \cdot 0(1)$ & $0.7(0)$ & $1 \cdot 2(0)$ \\
\hline Glx & $2 \cdot 1(0)$ & $2.9(0)$ & $1 \cdot 1(0)$ & $0.9(0)$ & $0.6(0)$ \\
\hline Ser & $14 \cdot 6(1)$ & $15.9(1)$ & $15.5(1)$ & $6 \cdot 4(2)$ & $24 \cdot 4(2)$ \\
\hline Gly & $3 \cdot 1(0)$ & $1.9(0)$ & $1.4(0)$ & $3 \cdot 6(1)$ & $0.8(0)$ \\
\hline His & $2.4(0)$ & $2 \cdot 5(0)$ & $3.5(0)$ & $0.0(0)$ & $2.0(0)$ \\
\hline Arg & $10 \cdot 6(1)$ & $10 \cdot 2(1)$ & $12 \cdot 0(1)$ & $3.8(1)$ & $13.4(1)$ \\
\hline Thr & $1.2(0)$ & $0.8(0)$ & $0 \cdot 3(0)$ & $0.7(0)$ & $0.5(0)$ \\
\hline Ala & $1.2(0)$ & $1.6(0)$ & $0.7(0)$ & $36 \cdot 3(10)$ & $1 \cdot 3(0)$ \\
\hline Pro & $0.5(0)$ & $0.0(0)$ & $0 \cdot 0(0)$ & $4 \cdot 4(1)$ & $0.4(0)$ \\
\hline Tyr & $0.0(0)$ & $0 \cdot 0(0)$ & $0 \cdot 2(0)$ & $3 \cdot 6(1)$ & $0.0(0)$ \\
\hline Val & $0 \cdot 2(0)$ & $0.5(0)$ & $0.0(0)$ & $18 \cdot 1(5)$ & $0.9(0)$ \\
\hline Met & $0.8(0)$ & $0.0(0)$ & $0.9(0)$ & $0.0(0)$ & $0.0(0)$ \\
\hline Cys & $0 \cdot 0(0)$ & $0.0(0)$ & $0.0(0)$ & $0.7(0)$ & $0.0(0)$ \\
\hline Ile & $0 \cdot 2(0)$ & $0 \cdot 0(0)$ & $0.7(0)$ & $0.1(0)$ & $0 \cdot 2(0)$ \\
\hline Leu & $0.0(0)$ & $0.0(0)$ & $0.0(0)$ & $5 \cdot 1(2)$ & $0.6(0)$ \\
\hline Dab + Phe & $38 \cdot 2(3)$ & $37.9(3)$ & $36 \cdot 5(3)$ & $15 \cdot 3(5)$ & $39 \cdot 2(3)$ \\
\hline Lys & $11 \cdot 0(1)$ & $11 \cdot 1(1)$ & $11 \cdot 1(1)$ & $0 \cdot 3(0)$ & $0 \cdot 2(0)$ \\
\hline
\end{tabular}

* Samples were hydrolysed, derivatized and analysed as described in Methods; molar percentages [( $\mathrm{mol}$ of each amino acid)/(mol of all amino acids) $\times 100$ ] are presented along with their estimated integer values (in parentheses). Pseudomycins $\mathrm{A}-\mathrm{C}$ were run in duplicate, pseudomycin $D$ in triplicate, and syringomycin as a single sample. The mean total number of nanomoles of amino acids for each of these samples was $6 \cdot 3,3 \cdot 7,2 \cdot 2,7 \cdot 6$ and $19 \cdot 1$, respectively.

† Separate analyses were done to identify 3-hydroxyaspartic acid [ $3(\mathrm{OH})$ Asp]. Plus and minus signs signify the presence or absence, respectively, of this amino acid.

After treatment, pseudomycins A, B and C, as well as syringomycin, produced $(\mathrm{M}+\mathrm{H})^{+}$ions shifted higher in mass by approximately $17-19 \mathrm{Da}$, equivalent to one molecule of ammonia or water. A second family of ions was also observed, in which masses were heavier by approximately 44-46 Da, equivalent to one molecule of ethanol $(46 \mathrm{Da})$. These data are consistent with a process in which the lactone is opened to an acid, amide or ester form. Additional evidence for this idea was obtained when 1-propanol, instead of ethanol, was used in the solvent for hydrolysis and dissolution. In this case, a different high-mass family was observed, approximately $60 \mathrm{Da}$ larger than that seen with the untreated molecules (Table 4). This increase is equivalent to the mass of 1-propanol. Pseudomycin D, on the other hand, lost approximately $16 \mathrm{Da}$ following both base treatments. This difference may represent loss of oxygen $(16 \mathrm{Da})$, or substitution of hydroxide for chloride (17 Da) as may occur, for example, at alkaline $\mathrm{pH}$ with chlorothreonine (Segre et al., 1989a). The behaviour of pseudomycin D, which was inconsistent with its being a lactone, along with its molecular mass, distinguish it from the other pseudomycins.
Ions with masses corresponding to those of the native molecules, of dehydrated molecules, of dimeric molecules, and of unidentified molecules were also observed, but at significantly lower levels than those of the +18 , +46 and $+60 \mathrm{Da}$ families.

\section{Amino acid composition of pseudomycins}

Amino acid analyses were performed on the pseudomycins and syringomycin, as described in Methods. 'Phe' refers both to Phe and Dab (diaminobutyric acid), since these molecules co-eluted from the HPLC. Pseudomycins $\mathrm{A}, \mathrm{B}$ and $\mathrm{C}$ had almost identical compositions, containing Asx, Ser, Arg, 'Phe' and Lys in the integer molar ratios $1: 1: 1: 3: 1$, respectively (Table 5). The unusual amino acid 3-hydroxyaspartic acid [3(OH)Asp] was also detected in each of the three molecules. Syringomycin contained Ser, Arg and 'Phe', in the integer molar ratios of $2: 1: 3$, as well as $3(\mathrm{OH})$ Asp. We did not detect significant amounts of aspartic acid or threonine in syringomycin. These data are consistent with those previously reported by Ballio et al. (1988), except that this group did not identify $3(\mathrm{OH})$ Asp in their amino acid analysis. The composition of pseudomycin D was more complex. Like the other pseudomycins and syringomycin, it contained Ser, Arg and 'Phe'. However, unlike the other pseudomycins, it did not have any Asx or Lys, but did have the additional amino acids Gly, Ala, Pro, Tyr, Val and Leu.

Although not resolved by reverse-phase HPLC, Phe and $\mathrm{Dab}$ are baseline-resolved by $\mathrm{CE}$ and can be quantified through their UV-absorption. The 'Phe' peaks from the amino acid analyser were thus collected and analysed in this way. Electropherograms of 'Phe' from pseudomycins A-D were essentially identical (data not shown). Electropherograms from pseudomycin B and from syringomycin are presented in Fig 3. The 'Phe' peak from pseudomycin B was composed entirely of $\mathrm{Dab}$, whereas the 'Phe' peak from syringomycin, as expected, contained $\mathrm{Dab}$ and $\mathrm{Phe}$ in a molar ratio of $2: 1$.

Pseudomycins $\mathrm{A}-\mathrm{C}$ have amino acid compositions clearly different from that of syringomycin (Table 5). They have one fewer Ser and contain one each of Asx and Lys, residues which are not detected in syringomycin. In addition, these pseudomycins contain three residues of Dab, whereas syringomycin contains two of Dab and one of Phe. Syringostatin A may be related to these pseudomycins but is structurally unique, containing Ser, Thr, dehydro-Thr, Dab, 3-hydroxyaspartic acid, chlorothreonine, homoserine, ornithine and a $\mathrm{C}_{14}$ fatty acid (Isogai et al., 1989). Syringotoxin, another pseudomonad antimycotic, has the same composition as syringostatin A except that it contains one Dab residue 


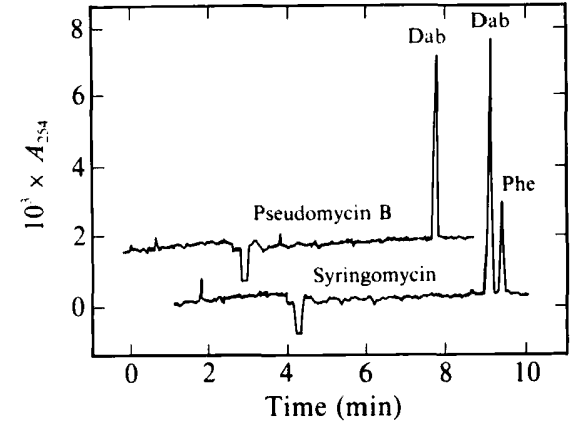

Fig. 3. Analysis of Dab and Phe by CE. 'Phe' peaks from HPLC analysis of hydrolysates of pseudomycin B (upper trace) and syringomycin (lower trace) were analysed by CE. Scales apply to syringomycin. For clarity of presentation, the pseudomycin B trace has been translated 1.3 min earlier, and $1.5 \mathrm{mAU}$ higher, than that of syringomycin. The molar ratio of PTC-Dab to PTC-Phe was 1.98, measured on a peak height basis using a value of 1.37 for the ratio $\varepsilon$ (PTC-Dab)/ $/ \varepsilon$ (PTC-Phe).

and one Gly residue (Ballio et al., 1990). The composition of pseudomycin $\mathrm{D}$ is clearly different from those of any of the other compounds.

\section{Structural comparison of the pseudomonad antimycotics}

Amino acid modifications may account for the unique but similar chromatographic, electrophoretic and mass spectrometric behaviour of pseudomycins A-C. In syringomycin, for example, fatty acid esterification, chlorination, hydroxylation and/or dehydration have all been reported (Segre et al., 1989a, b). The 16 Da difference between pseudomycins A and B could arise from esterifications with hydroxylated and unhydroxylated fatty acids, respectively. Similarly, pseudomycins $\mathrm{A}$ and $\mathrm{C}$ may contain fatty acids differing in length by two carbons $(28 \mathrm{Da})$. The inability of composition analysis to identify all such structural differences is not surprising since modified amino acids can be altered or destroyed during acid hydrolysis or may produce PTCamino acid derivatives which cannot be analysed using the automated chemistry currently available. Pseudomycins A-C may share other characteristics of syringomycin and syringostatin $\mathrm{A}$; for example being cyclic esters and amino-terminally $\mathrm{N}$-acylated. Solvent and $\mathrm{pH}$ stability experiments have suggested this to be true (Table 3), as have data from alkaline hydrolysis (Table 4). Additional support comes from the fact that automated Edman degradations have not yielded any useful sequence information from these pseudomycins. Amino-terminal pyroglutaminylation does not seem to explain this failure of the Edman chemistry, using the criterion that pyroglutamate aminopeptidase treatment does not result in successful sequence analysis (data not shown).
Table 6. Activity of pseudomycins (semipurified - Amberlite step) against several plant-pathogenic fungi

Pseudomycins $(10 \mu \mathrm{l})$ were applied to PDA plates at $10 \mu \mathrm{g} \mu \mathrm{l}^{-1}$, dried and then the plate oversprayed with spores and mycelial fragments of the fungus being tested. The culture medium and conditions used for testing each fungus are shown in Table $1 .+, \mathrm{A}$ zone of inhibition; -, no zone of inhibition. Readings were made after $5 \mathrm{~d}$. The experiment was replicated four times with identical results each time.

\begin{tabular}{lc}
\hline \multicolumn{1}{c}{ Fungus } & Activity \\
\hline Rynchosporium secalis & + \\
Ceratocystis ulmi & + \\
Cephalosporium gramineum & - \\
Pyrenophora teres & - \\
Pyrenophora graminea & - \\
Rhizoctonia solani & + \\
Botrytis allii & - \\
Sclerotinia sclerotiorum & + \\
Verticillium albo-atrum & + \\
Verticillium dahliae & + \\
Thielaviopis basicola & + \\
Fusarium oxysporum & + \\
Fusarium graminearum & - \\
Fusarium culmorum & + \\
\hline \hline
\end{tabular}

The most intriguing result is obtained by calculating theoretical average masses of syringomycin and pseudomycin A. The lactone of syringomycin contains, in addition to those residues quantified by amino acid analysis (Table 5), one each of $3(\mathrm{OH})$ Asp, 4-chlorothreonine, Dab and 3-hydroxydodecanoic acid (Segre $e t$ $a l ., 1989 a$ ), yielding a total mass of $1226 \cdot 8 \mathrm{Da}$. If one postulates that pseudomycin A contains one each of 3(OH)Asp, 4-chlorothreonine and 3-hydroxydecanoic acid, in addition to those residues reported in Table 5, its lactone would have a total mass of $1224.8 \mathrm{Da}$. These masses agree, within $0 \cdot 2$ and $0 \cdot 1 \mathrm{Da}$, respectively, with those actually observed (Table 4).

\section{Biological activities of the pseudomycins}

A semipurified preparation (Amberlite step) of the pseudomycins was toxic to a broad range of plantpathogenic fungi (Table 6). The most important among these include $V$. albo-atrum, Rhizoctonia solani and $F$. oxysporum. Thus, the culture extracts of $P$. syringae may prove to be useful tools for testing plants in various ways for control of diseases caused by these fungi. In addition, the bacterium itself may prove useful in biological control measures for a number of plant diseases, as was previously demonstrated for Dutch elm disease (Lam $e t$ al., 1987; Scheffer, 1989).

Since $P$. syringae is associated with plants, it seemed logical to test pseudomycin $\mathrm{A}$ for its phytotoxic effects on an assortment of monocots and dicots. No effect was 
Table 7. The phytotoxic effect of pseudomycin $A$ on monocotyledonous and dicotyledenous plants

\begin{tabular}{|c|c|c|c|}
\hline \multirow[b]{2}{*}{ Plant } & \multicolumn{3}{|c|}{ Amount of pseudomycin A applied* } \\
\hline & $1 \mu \mathrm{g}$ & $5 \mu \mathrm{g}$ & $10 \mu \mathrm{g}$ \\
\hline \multicolumn{4}{|l|}{ Monocots } \\
\hline Oryza sativa (rice) & + & + & + \\
\hline Triticum aestivum (wheat) & + & + & + \\
\hline Zea mays (maize) & + & + & + \\
\hline $\begin{array}{l}\text { Phleum pratense } \\
\text { (common timothy) }\end{array}$ & - & - & - \\
\hline \multicolumn{4}{|l|}{ Dicots } \\
\hline Cassia tora (sickle pod) & - & + & + \\
\hline $\begin{array}{l}\text { Helianthus annus } \\
\text { (common sunflower) }\end{array}$ & + & + & + \\
\hline Cucumis sativus (cucumber) & + & + & + \\
\hline $\begin{array}{l}\text { Lycopersicon esculentum } \\
\text { (tomato) }\end{array}$ & - & + & + \\
\hline
\end{tabular}

$*+$, Development of a zone of necrosis on the leaf; - , no necrosis For details see Methods. The experiment was repeated twice with identical results.

Table 8. Minimal inhibitory concentrations of pseudomycin $A$ against fungal pathogens of humans

\begin{tabular}{llcc}
\hline \hline & \multicolumn{3}{c}{ MIC $\left(\mu \mathrm{g} \mathrm{ml}^{-1}\right)^{*}$} \\
\cline { 2 - 4 } \multicolumn{1}{c}{ Organism } & $24 \mathrm{~h}$ & $48 \mathrm{~h}$ & $72 \mathrm{~h}$ \\
\hline Candida albicans $89-80$ & $3 \cdot 12$ & 25 & ND \\
Candida albicans $89-96$ & $3 \cdot 12$ & $12 \cdot 5$ & ND \\
Candida tropicalis & $3 \cdot 12$ & $6 \cdot 25$ & ND \\
Cryptococcus neoformans & $1 \cdot 56$ & $3 \cdot 1$ & ND \\
Bipolaris spicifera & ND & $12 \cdot 5$ & $>50$ \\
Aspergillus fumigatus & ND & $12 \cdot 5$ & 50 \\
\hline \hline
\end{tabular}

* MIC is defined as the minimal concentration required to cause an inhibition of fungal growth as judged by the turbidity of the broth suspension.

observed on any plant with the direct application of pseudomycin A (or semipurified preparation of the pseudomycins) unless a puncture wound was made in the leaf (according to the assay procedure; data not shown). Many species of both monocots and dicots were sensitive while some, such as tomato and sickle pod, showed a dose effect, whereas common timothy was totally insensitive to pseudomycin $\mathrm{A}$ at the concentrations tested (Table 7). Thus, pseudomycin A might be considered a host-selective phytotoxin within the dose range tested.

Although each of the pseudomycins demonstrated activity against Geotrichum candidum (data not shown), pseudomycin $\mathrm{A}$, because of its relative abundance in culture, was chosen for MIC tests against fungal pathogens of humans. Cryptococcus neoformans was particularly sensitive to pseudomycin, but the MICs were within one order of magnitude of each other for all of the fungi tested (Table 8). Many of these fungi cause opportunistic infections in immunologically compromised patients, such as those suffering from AIDS. The most common treatment currently available for these systemic mycoses is administration of the highly toxic antibiotic amphotericin B (Merck, 1987). Since pseudomycins retain their antimycotic activity in human serum and appear to be non-toxic in preliminary tests in mice (data not shown), they may have potential use as an alternative to amphotericin B in the treatment of these diseases.

The authors would like to acknowledge the expert technical assistance of Mr John Racs, Ms Christine Acklin, Ms Tammy Bauer, and $\mathrm{Mr} \mathrm{Haul} \mathrm{Wong.} \mathrm{We} \mathrm{thank} \mathrm{Dr} \mathrm{Dan} \mathrm{Marshak} \mathrm{for} \mathrm{critical} \mathrm{reading} \mathrm{of}$ the manuscript. This work was supported by NSF grant DMB-860 7347, NIH and the Montana Agricultural Experiment Station (G.S.), and by NSF grant DIR86-18937 (D.B.T.).

\section{References}

Ballio, A., Barra, D., Bassa, F., DeVay, J. F., Grguring, I. lacobellis, N. S., Marino, G., Pucci, P., Simmaco, M. \& Surio, G. (1988). Occurrence of multiple forms of syringomycin. Physiological and Molecular Plant Pathology 33, 493-496.

Ballio, A., Barra, D., Bassa, F., DeVay, J. F., Grguring, I., Iacobellis, N. S., Marino, G., Pucci, P., Simmaco, M. \& Surio, G. (1989). Occurrence of multiple forms of syringomycin. In Phytotoxins and Plant Pathogenesis (NATO ASI series, vol. H27), pp. 363-366. Edited by A. Graniti, and others. Berlin: Springer-Verlag.

Ballio, A., Bossa, G., Collina, A., Gallo, M., Iacobellis, N. W., Paci, M., Pucci, P., Scaloni, A., Segre, A. \& Simmaco, M. (1990). Structure of syringotoxin, a bioactive metabolite of Pseudomonas syringae pv. syringae. FEBS Letters 269, 377-380.

Bidwai, A. P., Zheng, L., BachmanN, R. C. \& Takemoto, J. (1986) Mechanism of action of Pseudomonas syringae phytotoxin, syringomycin. Plant Physiology 83, 39-43.

Davison, J. (1988). Plant beneficial bacteria. Bio/Technology 6, 282286.

Difco (1984). Difco Manual 10th edn. Detroit, Michigan: Difco Laboratories.

FraVEL, D. R. (1988). Role of antibiosis in the biocontrol of plant diseases. Annual Review of Phytopathology 26, 75-91.

Gross, D. C., DeVay, J. E., \& Stadtman, F. H. (1977). Chemical properties of syringomycin and syringotoxin; toxigenic peptides produced by Pseudomonas syringae. Journal of Applied Bacteriology 43, 453-463.

Isogai, A., Gukuchi, N., Yamashita, S., Suyama, K. \& Suzuki, A. (1989). Syringostatins, novel phytotoxins produced by Pseudomonas syringae pv. cynodontis. Agricultural and Biological Chemistry 53, $3117-3119$.

lam, B. S., Strobel, G. A., Harrison, L. A. \& Lam, S. R. (1987). Transposon mutagenesis and tagging of fluorescent Pseudomonas: antimycotic production is necessary for control of Dutch elm disease. Proceedings of the National Academy of Sciences of the United States of America 84, 6447-6451.

MERCK (1987). Merck Manual of Diagnosis - Therapy. Rahway, NJ : Merck Sharp \& Dohme Research Laboratories 
Rinaldi, M. G. \& Howell, A. W. (1988). Antifungal antimicrobics : Laboratory evaluation. In Diagnostic Procedures for Mycotic and Parasitic Diseases, 7th edn, pp. 325-356. Edited by B. B. Wentworth. Washington, DC: American Public Health Association.

Myers, D. F. \& Strobel, G. A. (1983). Pseudomonas syringae as a microbial antagonist against $C$. ulmi in the apoplast of American elms. Transactions of the British Mycological Society 506, 389-394.

Sakthivel, N. \& Gnanamanicham, S. S. (1987). Evaluation of Pseudomonas fluorescens for suppression of sheath rot diseases and for enhancement of grain yields in rice (Oryza sativa L.). Applied and Environmental Microbiology 53, 2056-2059.

SCHEFFER, R. J. (1983). Biological control of Dutch elm disease by Pseudomonas species. Annals of Applied Biology 103, 21-30.

SCHEFfER, R. J. (1989). Pseudomonas for biological control of Dutch elm disease. III. Field trials at various locations in the Netherlands. Netherlands Journal of Plant Pathology 95, 305-318.

Segre, A., Bachmann, R. C., Ballio, A., Bossa, F., Grgurina, I., Iacobellis, N. S., Marino, G., Pucci, P., Summaco, N. \& TAKEMOTO, J. Y. (1989a) The structure of syringomycin A, E, and G. FEBS Letters 255, 27-31.
Segre, A., Ballio, A., Barra, D., Bossa, F., Grgurina, I., Iacobellis, N. S., Marino, G., Pucci, P., Simmaco, M. \& Surico, G. (1989b). Structural studies on syringomycin. In Phytotoxins and Plant Pathogenesis (NATO ASI series, vol. H27), pp. 367-371. Edited by A. Graniti. Berlin: Springer-Verlag.

Stark, M. P., Stolp, H., Trüper, H. G., Balows, A. \& Schlegel, H. G. (1981). The Prokaryotes, vol. 1. Berlin: Springer-Verlag.

Sugawara, F., Strobel, G. A., Fisher, L. E., VanDuyne, G. D. \& Clardy, J. (1985). Bipolaroxin, a selective phytotoxin produced by Bipolaris cyndontis. Proceedings of the National Academy of Sciences of the United States of America 82, 8291-8294.

Thomashow, L. A. \& Weller, D. M. (1988). Role of phenazine antibiotic from Pseudomonas fluorescens in biological control of Gaeumannomyces graminis var. tritici. Journal of Bacteriology 170, 3499-3508.

Voisard, C., Keel, C., HaAs, D. \& Defago, G. (1989). Cyanide production by Pseudomonas fluorescens helps suppress black rot of tobacco under gnotobiotic conditions. EMBO Journal 8, 351-358.

WELLER, D. M. (1988). Biological control of soilborne plant pathogens in the rhizosphere with bacteria. Annual Review of Phytopathology 26, 379-407. 